\title{
New Hydroxamic Acid Derivative Prevents Sq-OOH Induced Wrinkle
}

\author{
Ho Sik Rho, Heung Soo Baek, Byoung-Seok Lee, Ji Hyun Kim, Duck Hee Kim, and Ih Seop Chang
}

\author{
$R \& D C$ Center, AmorePacific Cofporation, Yongin, Gyeonggi-do 446-729, Korea. "E-mail: hiocarbon(thfreechal.com \\ Recened August 12, 2005
}

Key Words : Hydroxamic acid. Lipid peroxidation, Sq-OOH, Epidermal aging

Lipid peroxidation has been suggested to play a key role in damaging biological processes resulting from excessive exposure to UV light.' $\Lambda$ ging of skin has been associated with increased peroxidation of skin lipid. ${ }^{2}$ In particular, squalene, which is a main component of skin surface polyunsaturated lipids, is easily peroxidized. 'S Squalene-monohydroperoxide ( $\mathrm{Sq}-\mathrm{OOII}$ ), the initial product of peroxidized squalene, is produced at the human skin by natural exposure to sunlight during day time activities.

Recently, a few researchers reported on the damages of hairless mice skin by the topical application of Sq-OOlI. ${ }^{+}$ Repeated application of Sq-OOII to the hairless mice induced its the skin wrinkles with clear and fine appearance. ${ }^{\text {to }}$ Ilistologically were seen, more keratinocyte hypertrophy with Sq-OOII treated skin than with chronic UVB irradiated group in epidermis. In dermis, characteristics, found in UVB irradiated skin, such as the loss of polarity, fractured collagen bundle and elastosis, were not observed severely. The alteration of epidermal layer might be the main factor for the formation of wrinkle caused by $\mathrm{Sq}-\mathrm{OOH}$. From the previous works, ${ }^{4} \mathrm{Sq}-\mathrm{OOH}$ is considered as an important source of damage in the early stage of aging process to result in epidermal wrinkle. Thus, it is very important to minimize such damage that would be induced mainly by $\mathrm{Sq}-\mathrm{OOH}$ against healthy skin condition. Therefore, we tried to develop new anti-aging materials for protecting skin damage by $\mathrm{Sq}-\mathrm{OOH}$. Hydroxamic acids, the naturally occurring products exhibit low toxicities in general, and are of interest for many therapeutic applications. " Recently, hydroxamic acids and derivatives were reported largely as effective antibacterial and antifungal agents. ${ }^{6}$ Their activities originate from their ability to coordinate on metal ions. ${ }^{7}$ That is, hydroxamic acid group is regarded as an one electron donor. Hydroxamic acid moiety has also drawn much attention as a reactive oxygen species (ROS) scavenger."

In this study, a new skin protecting compound, (4- $(\mathrm{N}$ hydroxycarbamoyl)phenyl)- $N$-adamantanylcarboxamide (1)

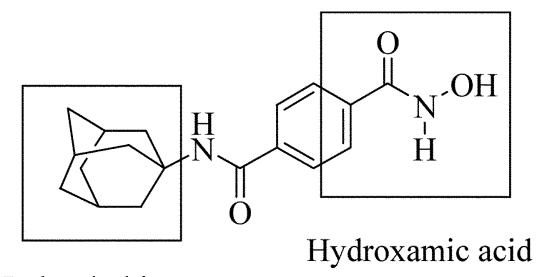

Hydrophobic part 1

Figure 1. Structure of hydroxamic acid derivative.

is synthesized to show inhibitory activities of lipid peroxidation both in vitro and in vivo. The targeted compound $\mathbf{1}$ is a hydroxamic acid derivative which possesses an amide linker between hydroxamic acid and adamantane moiety. Adamantane group was adopted as a hydrophobic moiety to optimize antioxidant activity of hydroxamic acid in animal test. Compound $\mathbf{1}$ is believed to be adequate in skin permeation because of its balance in hydrophilic and hydrophobic character.

\section{Experimental Section}

Synthesis. Mono-methyl terephthalate 2 was refluxed in thionyl chloride to afford an acid chloride. This compound was reacted immediately with $\mathrm{l}$-adamantamine $\mathrm{HCl}$ in pyridine to produce the corresponding amide derivatives 3 . The ester group was hydrolyzed under standard condition $(\mathrm{NaOH}$, ethanol) to produce corresponding acid 4 . The acid was reacted with ethylchloroformate and $N$-methyl morpholine in THF to convert the carboxylic acid to an anhydride. ${ }^{9}$ The anhydride was reacted immediately with hydroxylamine $\mathrm{HCl}$ to produce the corresponding hydroxamic acid derivative 1 .

TLC, $\mathrm{SiO}_{2}, \mathrm{EtOAc} /$ hexanes $2: \mathrm{l}, \mathrm{R}_{\mathrm{i}}=0.4 \mathrm{l}{ }^{1} \mathrm{H}-\mathrm{NMR}(300$ $\left.\mathrm{MHz}, \mathrm{DMSO}-\mathrm{d}_{6}\right) \delta 11.20(\mathrm{~s}, \mathrm{lH}), 9.12(\mathrm{~s}, 1 \mathrm{H}), 7.80(\mathrm{~m}, 4 \mathrm{H})$, $7.61(\mathrm{~s}, \mathrm{lH}), 2.10(\mathrm{~s}, 9 \mathrm{H}), 1.78(\mathrm{~s}, 6 \mathrm{H})$. IR $v_{\max }(\mathrm{KBr}) 3298$,<smiles>COC(=O)c1ccc(C(=O)NC23CC4CC(C2)C(C(C)(C)C)(C4)C3)cc1</smiles>
2

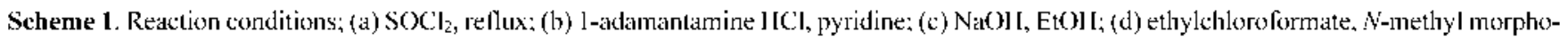
line, THF: (e) hydroxylamine IICI. TEA, DMF 
$2911,1634,1542 \mathrm{~cm}^{-1}$. Ms-FAB (m/e) $315\left(\mathrm{M}^{+}+1\right)$.

DPPH assay. DPPH reagent was prepared at a DPPH concentration of $80 \mu \mathrm{g} / \mathrm{mL}$ in $\mathrm{MeOH}$. A test sample $(50 \mu \mathrm{L})$ was dissolved in DMSO and mixed with $100 \mathrm{mM}$ Tris-HCl buffer $(\mathrm{pH} 7.4,50 \mu \mathrm{L})$, distilled water, and $400 \mathrm{~mL}$ of DPPH ethanolic solution $(50 \mu \mathrm{L})$. The mixture was shaken well and allowed to stand for $20 \mathrm{~min}$ in the dark. The absorbance was measured at $515 \mathrm{~nm}$ using an Elx800 microtiter plate reader (Bio-Tek Instruments, Venmont, USA)

MTT growth assay. HaCaT keratinocytes were maintained in DMEM (Gibco, Grand Island, NY, USA) supplemented $10 \%$ fetal bovine serum, previously inactivated at 56 ${ }^{\circ} \mathrm{C}$ for $20 \mathrm{~min}$. The cytotoxic effects of test materials were monitored by 3-(4,5-dimethylthiazol-2-yl)-2,5-diphenyltetrazolium bromide (MTT) assay as dose dependent manner.

Lipid peroxidation. $\mathrm{HaCaT}$ keratinocytes were grown in DMEM medium containing $10 \%$ fetal bovine serum and $1 \%$ antibiotic and antimycotic solution. For experiments, cells were maintained in DMEM supplemented with $1 \%$ fetal bovine serum (FBS) and test materials for $18 \mathrm{~h}$. After $\mathrm{HaCaT}$ keratinocytes were incubated with test materials for $18 \mathrm{~h}$, the cells were exposed to $4 \mathrm{mM} t-\mathrm{BOOH}$ for $4 \mathrm{~h}$. Following incubation, the cell were washed twice in phosphate-buffered saline (PBS), and lysed by repetitive freeze/thawing in distilled water. To establish the levels of lipid peroxidation, malondialdehyde (MDA) and 4-hydroxy$2(E)$-nonenal (4-HNE) levels were quantified using a commercial colorimetric lipid peroxidation assay kit (Calbiochem, San Diego, CA). This method analyzes MDA and 4$\mathrm{HNE}$ by their reaction with a chromogen ( $N$-methyl-2phenylindole) at $45^{\circ} \mathrm{C}$ to produce a stable chromogen. The reaction products were measured by spectrophotometry at $586 \mathrm{~nm}$. The procedure was performed in accordance with the manufacturer's specifications and data were expressed in $\mu \mathrm{mol} / \mathrm{mg}$ protein.

Animal. Female SHR-1 hairless mice (Charles River, Japan), age ranges of 7-8 weeks, were used. They were housed 5 per cage ( 10 mice per groups) in a temperature ( 23 $\pm 3{ }^{\circ} \mathrm{C}$ ) and the relative humidity $(40-60 \%)$ controlled room. Lighting was adjusted automatically to give a cycle of 12 hours light and 12 hours dark. Throughout the study, the animals were allowed to access freely to laboratory diets (Purina Co., Korea) and tab water. The water analysis for bacteriologic and chemical contaminant was regularly conducted by local water supply authority. No contaminants were present in diet or water to the levels of interfering with the objective of the study. One week of acclimatization period, was allowed before any treatment. Both animal care and protocol for this study were in accordance with IACUC (Institutional Animal Care and Use Committee) and OECD guideline

Sq-OOH preparation and treatment. The procedure for preparation of $\mathrm{Sq}-\mathrm{OOH}$ has been described previously. ${ }^{40.4 \mathrm{t}}$ Briefly, $\mathrm{Sq}-\mathrm{OOH}$ was produced from squalene by UVA irradiation $\left(50 \mathrm{~J} / \mathrm{m}^{2} / \mathrm{S}\right)$. UV-irradiated squalene containing $\mathrm{Sq}-\mathrm{OOH}$ was extracted with methanol. The methanol solution was displaced with ethanol solution by evaporation under a nitrogen gas stream. Sq-OOH was confirmed for the hydroperoxide assay by HPLC coupled with chemiluminescence's detection. In group 2 and 3 , mice were treated with $0.1 \mathrm{~mL}$ of Sq-OOH. Treatment was applied to the dorsum (neck to tail area, constituting an area of approximately 20 $\mathrm{cm}^{2}$ ) using a plastic pipette, 2 times $/ 7$ day/weeks for 4 weeks. Skin samples were taken at 4 week. To group $3,0.1$ $\mathrm{mL}$ of ethanol solution containing $1 \%$ compound 1 was applied to the dorsum at $90 \mathrm{~min}$ prior to $\mathrm{Sq}-\mathrm{OOH}$ treatment.

Evaluation of skin wrinkle. Treated animals were estimated grossly and photographed by digital camera (C740uz, Olympus ${ }^{\text {is }}$, Japan) for evaluation of skin wrinkling. Skin replica image was acquired for statistical analysis. Skin negative replicas were made of the dorsum using a siliconbased gum material (Silflo, Flexico Development Ltd., UK). Animals were anesthetized with pentobarbital, and silflo was applied according to the manufacture's instructions. The appearance of wrinkles was assessed using an image analysis method. In brief, replicas were illuminated under an illumination lamp at an angle of 20 degree to maximize the formation of shadows behind the wrinkles. The image was observed under a stereoscopic microscope and photographed using a CCD camera installed with skin-visiometer SV600 software $(\mathrm{C}+\mathrm{K}$, Germany). Results of raw data were R1-R5 by analysis of the horizontal line. Each parameter acquired by horizontal analysis of replica image mean as follows;

Histology of skin. Animals were sacrificed at the end of the study. Dorsal skin was removed, and adherent subcutaneous fat was dissected away. Skin specimens obtained from dorsal skin were fixed in $10 \%$ buffered formalin, embedded in paraffin and sectioned 3-4 $\mu \mathrm{m}$ for light microscopy. Sections were stained with $\mathrm{H} \& \mathrm{E}$, and MassonTrichrome stain for collagen.

\section{Results and Discussion}

To evaluate antioxidant effect of hydroxamic acid derivative 1, we compared its activity with known antioxidant such as trolox, ${ }^{10}$ EGCG $^{11}$ and kojic acid. ${ }^{12}$ Diphenylpicrylhydrazyl (DPPH) is widely used for assessing the ability of antioxidant agent to transfer labile $\mathrm{H}$-atoms to radicals, a common mechanism of radical scavenging. Trolox and EGCG showed a potent scavenging activity (Table 1). Compound 1 showed mild scavenging activity $\left(\mathrm{CC}_{50}=43.7\right.$ $\mathrm{mM})$. However, compound $\mathbf{4}$ (4-( $\mathrm{N}$-adamantanylcarbamoyl)benzoic acid) which is the precursor of hydroxamic acid derivative showed no inhibitory activity. These results suggest that the presence of hydroxamic moiety was critical for radical scavenging activity. Kojic acid showed no activity.

Lipid peroxidation is an indicator of possible free radical damage to cells. Cytotoxicity and inhibitory potency of compound $\mathbf{1}$ in lipid peroxidation were evaluated in HaCat cells. Cell viability was assessed by the MTT reduction assay. HaCat cells were resistant to up to $10 \mu \mathrm{M}$ concentration of all test materials (Fig. 2).

After confirming cell viability, we evaluated inhibitory activity of compound $\mathbf{1}$ in lipid peroxidation. Their activities 
Table 1. Radical-scavenging Frfects

\begin{tabular}{cc}
\hline Compound & DPPH ICs $(\mu \mathrm{M})$ \\
\hline Trolox & 20.7 \\
EGCG & 1.52 \\
Kojic acid & - \\
Compound I & 43.7 \\
Compound 4 & - \\
\hline
\end{tabular}

$-:$ Nol eflective.

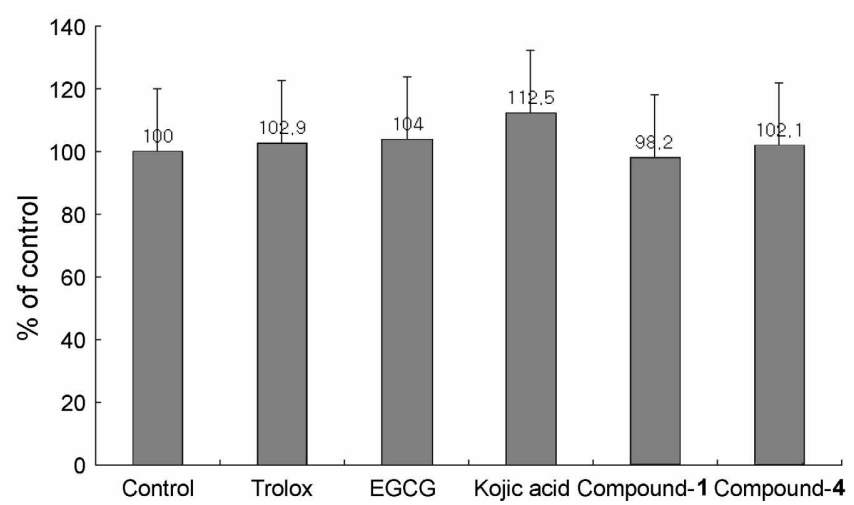

Figure 2. Cytoloxic effects of test compounds in $\mathrm{HaCat}$ cell line. All compounds were tested at $10 \mu \mathrm{M}$ concentration.

were examined in terms of ability to reduce the oxidative lactors such as malondialdehyde (MI) $\Lambda$ ) and 4-hydroxy2(E)-nonenal (4-IINF), gencrated by TBITP (tert-butylhydroperoxide) in I laCaT cell line. Treatment of $4 \mathrm{mM}$ of TBIIP increased lipid peroxide level up to about three times as compared with untrated sample. When $10 \mu \mathrm{M}$ of compounds were treated, trolox, FGCG and compound 1 ((4-\{ $N$-hydroxycarbamoyl)phenyl)- $N$-adamantanylcarboxamide) were active (Fig. 3). Trolox decreased the level of lipid peroxidation by about $40 \%$ in contrast with TBHP-

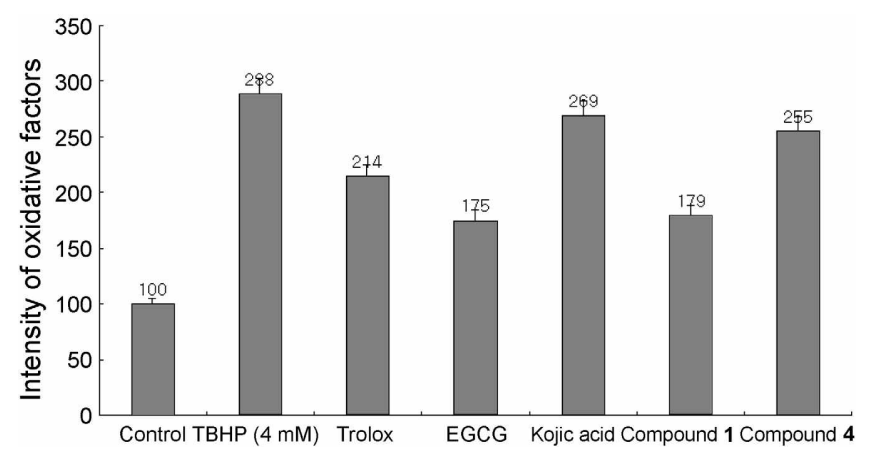

Figure 3. Inhibitory ellees on lipid peroxidation induced by TBHP in HaCat cell line. All compounds were lested at $10 \mu \mathrm{M}$ concentration.

treated control. Reduced lipid peroxidation level was obtained about $50 \%$ after being treated with compound 1 , which was close to the effect with EGCG. In this assay, compound $\mathbf{4}$ and kojic acid also showed no inhibitory activity at the same concentration.

In addition, the effect of compound 1 on the wrinkle formation by $\mathrm{Sq}-\mathrm{OOH}$ was investigated in order to evaluate its availability for suppressing the lipid peroxidation in animal model. The features of the dorsal skin and replica images of hairless mice in groups I [vehicle, \$q-OOI(-)], group 2 [vehicle, $\mathrm{Sq}-\mathrm{OOH}(+)$ ] and group 3 [compound $\mathbf{1}$, $\mathrm{Sq}-\mathrm{OOIJ}(+)]$ were shown in Figure 4 . At the end of 4-week topical application period, all the mice in S4-OOII treated group exhibited wrinkles with clear and line appearance $(\wedge 2$ and $B 2$ ). Ilowever, reduced wrinkle was observed in the mice group 3 ( $\wedge 3$ and $B 3$ ). Based on these results, it is suggested that the application of compound 1 prevents the formation of wrinkle induced by Sc-OOH.

$\Lambda t$ the end of experimental period, the skin sections were cul and stained with II\&F, and Masson-Trichrome stain for collagen. $\triangle$ lot of alteration in epidermal layer was seen in

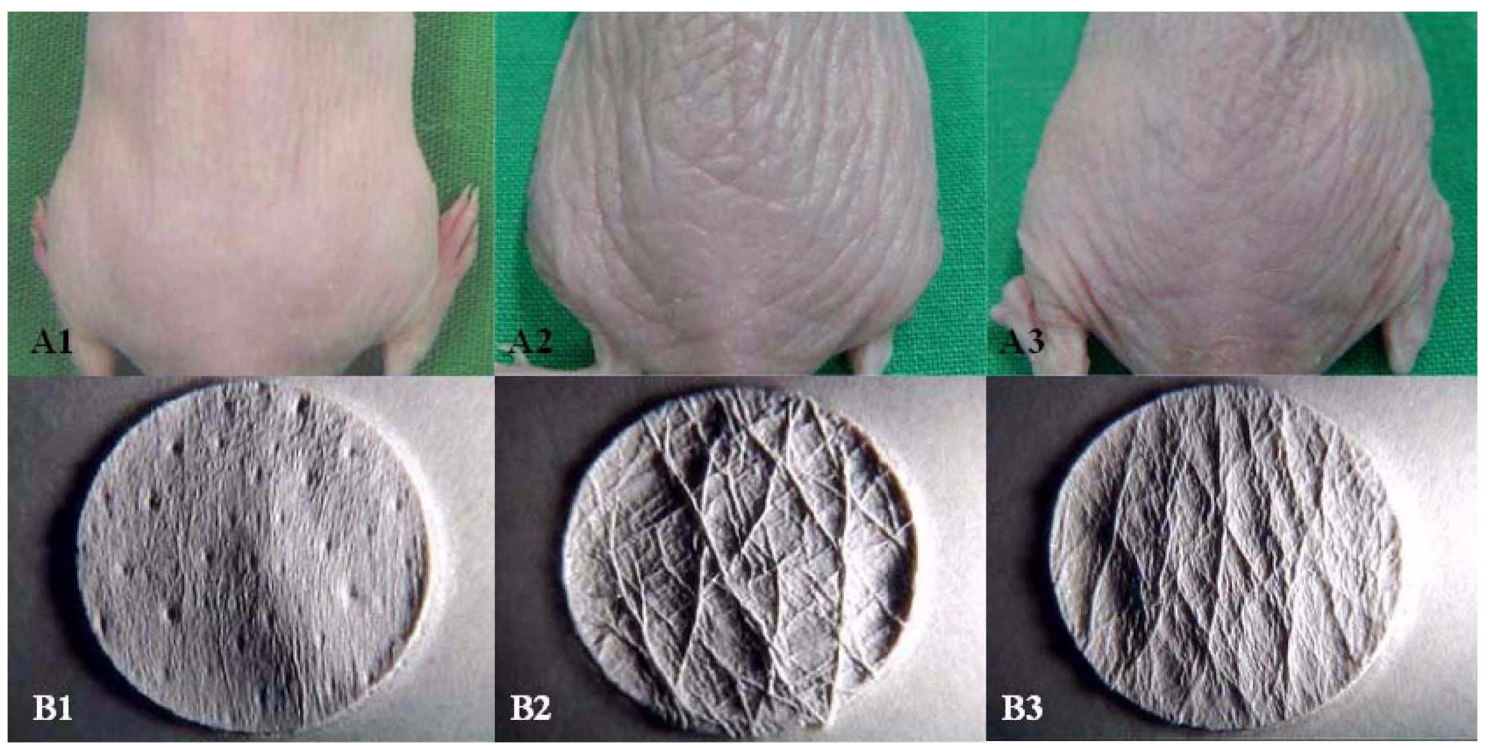

Figure 4. Pholographs of skin surlace $(\Lambda)$ and replica image (B) of hairless mouse. 1: Lntreated skin. 2: Sq-OOI lrealed skin, 3: Sq-OOI and compound $I$ trealed skin. 


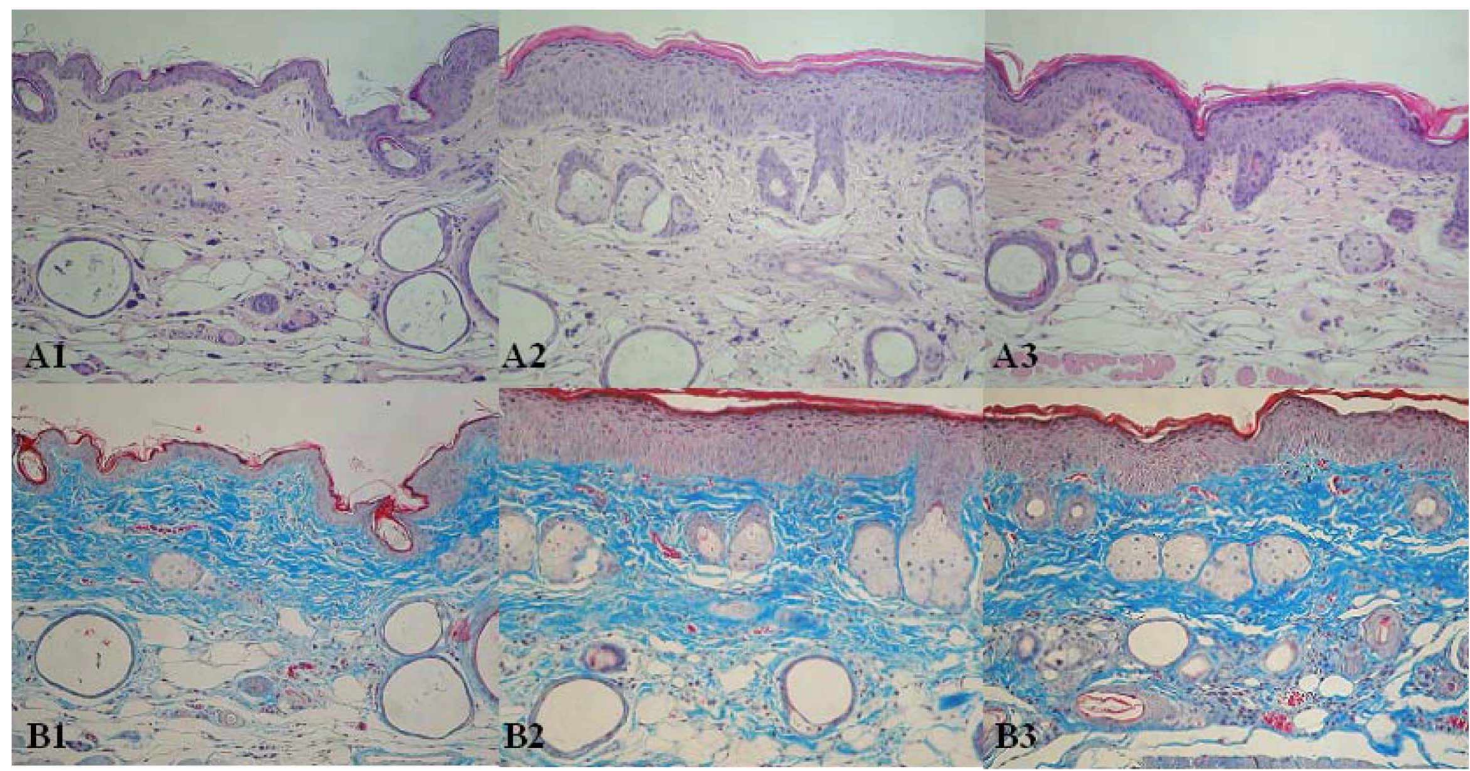

Figure 5. Itistological lindings of hairless mouss. I: Untrealed skin. 2: Sq-OOI treated skin. 3: Sq-OOI and compound 1 lealed skin. $A$, Ilematoxyline \& Hosin slain. 13. Masson \& Trichrome slain, Original magnification X 160

$\mathrm{Sq}$-OOII treated animal such as hypertrophy, hyperkeratosis and increasing epidermal thickness $(\triangle 2$ and $B 2)$. Epidemal thickness was particularly increased up to three times as compared with the untrealed skin. Ilowever, a change of dermis layer was not signilicant. The formation of wrinkle induced by $\mathrm{Sc}$-OOI may not be due to not alteration of dermal layer but to alteration of epidermal layer. The application of compound 1 suppressed alteration in epidermis layer to the Sq-OOII nol application ( $\triangle 3$ and B.3). These histological data are correlated fairly well with features of dorsal skin and replica images.

In our best knowledge, this is the lirst report showing that an antioxidant agent prevents $\mathrm{Sq}-\mathrm{OOII}$ induced wrinkle formation in vivo. Hydroxamic acid has both radical scavenging activity and iron chelating activity. The availability of new hydroxamic acid derivative 1 as a radical scavenger should contribute to the suppression of damage induced by $\mathrm{Sq}-\mathrm{OOI}$.

\section{References}

I. (a) Meffert, I.: Diezel, W.: Sonnichsen, H. Frperientia 1976, 32, 1397. (b) (hamberlain, J.: Moss, S. 1I. Photochem. Photobiol. $1987,45,625$.

2. (a) Uchino. T.; Tokunaga, II.; Onodera, II.; Ando, M. Biol. Phum. Bull. 2002, 25, 605. (b) Ohsawa. K.; Watanabe, $T_{\text {; }}$ Matsukawa,
R.: Yoshimura, Y.: Imacda, K. J. Toxicol Sci 1984, 9, 151.

3. (a) Kwon, T. W.; Olcott, II. S. J. Food Sci. 1966, 3/, 552. (b) Yco, II. C. II.; Shibamoto. T. Lijwis 1992, 27, 50 .

4. (a) Chiba, K.; Sonc. T.: Kawakami, K.: Onou, M. Exp. Itemutol 1999, 8, 471. (b) Chiba, K.: Kawakami. K.: Sone, T.: Onoue, M. Shin Phamocologl and dpplied Shin Phrsologi 2003, 16, 242.

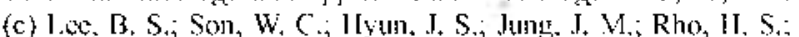
Kim, D. H.; Shim, Y. C.: Kim, B. H. Laboraton' Animat Research $2005,21,5$.

5. Vanjari, II; Pande, R. Journat of Phomacemical and Biochemicat Andisis 2003,33,783.

6. Jackman, I. [.; Fierke; C. A.; Tumey, L. N.; Pirung, M.; lichiyama, T.; Tahir, S. II.; l lindsgatl, O.; Ractz, C. R. I1. Wouthal of Biological Chemistry $\mathbf{2 0 0 0}, 275,11002$.

7. Farkas, E.; Enyedy, E. A.; Micera, G; Garribba, E. Pollhedron 2000, 79,1727 .

8. Taira, J.; Miyagi, C., Aniya, Y, Biochemical Phormocologr 2002. 63.1019.

9. Reddy, A. S.; Kumar, M. S.: Ruddy, C. R. Tenahothon Lett. $20 \% 0$, 41,6285 .

10. (a) Peus, D.; Meves, A.; Pott, M.; Beycrle, A.; Pittelkow, M. R. Free Ratic. Biol. Wfed. 2001, 30, 425. (b) Delicado. E. N.; Ferrer; A. S.: Carmona, F. G. Biochimica ef Bioptrisicu Actu 1997, /335, 127.

11. (a) Saffari, Y.; Ilossein Sadizadeh, S. M. Life Science's 2004, 74. 1513. (b) Bors, W. Michel, C. Free Ratic: Biol. Mat. 1999, 27 , 1413.

12. Mitani, I1.; Koshiishi, I.; Sumita, T.; Imanari, T. Furopean Journol of Pham macologr 2001, 4//, 169. 